\title{
Evidences of Impacts of Climate Change on Mediterranean Biota
}

\author{
Núria Marbà ${ }^{1 *}$, Gabriel Jordà ${ }^{2}$, Susana Agustí ${ }^{1,3}$ and Carlos M. Duarte ${ }^{1,3}$ \\ ${ }^{1}$ Department of Global Change Research, Institut Mediterrani d'Estudis Avançats (Consejo Superior de Investigaciones \\ Científicas-Universitat de les Illes Balears), Esporles, Spain, ${ }^{2}$ Department of Marine Resources and Ecology, Institut \\ Mediterrani d'Estudis Avançats (Consejo Superior de Investigaciones Científicas-Universitat de les Illes Balears), Esporles, \\ Spain, ${ }^{3}$ Biological and Environmental Sciences and Engineering, Red Sea Research Center, King Abdullah University of \\ Science and Technology, Thuwal, Saudi Arabia
}

Keywords: SST, SST anomaly, species, biological traits, activation energy

\section{OPEN ACCESS}

Edited by:

Alberto Basset,

University of Salento, Italy

Reviewed by:

Ulisses Miranda Azeiteiro, Open University of Portugal and University of Coimbra, Portugal Jose M. Riascos,

Universidad de Antofagasta, Chile

*Correspondence:

Núria Marbà

nmarba@imedea.uib-csic.es

Specialty section: This article was submitted to Marine Ecosystem Ecology, a section of the journal Frontiers in Marine Science

Received: 07 October 2015 Accepted: 11 January 2016 Published: 28 January 2016

Citation:

Marbà N, Jordà G, Agustí S and Duarte CM (2016) Evidences of Impacts of Climate Change on Mediterranean Biota.

Front. Mar. Sci. 3:3.

doi: 10.3389/fmars.2016.00003
We report here the data set entitled "Impacts of climate change on organisms in the Mediterranean Sea," which is the basis for the analysis of impacts of climate change on marine organisms presented by Marbà et al. (2015a). The data is deposited at Digital CSIC, the institutional repository of the Spanish National Research Council, and can be accessed at http://hdl.handle.net/10261/116098 (Marbà et al., 2015b).

In this data set we compiled evidence of warming on Mediterranean Sea biota derived from published reports. These were derived from a broad literature search conducted through the ISI Web of Knowledge, completed in December 2014. Hence, the data set contains information published until year 2014. The search was conducted using the keywords "(Mediterranean) AND ((Bio* OR Eco*)) AND ((warming OR temperature)) AND ((Marine OR Ocean*)) NOT $(($ paleo*))."

The output of this search was then screened to extract information only for articles that explicitly attributed the changes observed in marine biota to warming. We derived, for each data set extracted from the literature, metadata including the year or period of years of the study, name and coordinates of the study site, species name, taxonomic group, and some key traits of the species studied, such as whether the species were sessile or mobile, and whether they were native or introduced. We also extracted metadata on the biological trait examined, which was classified by type of trait and which magnitude was also extracted. The biological traits examined were very diverse and were classified into six main groups: abundance, survival, fertility, migration, phenology, and growth. Some reports addressed single species whereas others reported traits from communities or assemblages, such as phytoplankton and zooplankton. The data set includes both qualitative and quantitative assessment of impacts, but only those providing quantitative assessments were analyzed in detail. The minimum data required to examine the frequency of impacts with temperature were identification of the species or community examined, the location of the study (which could include the entire basin) and the year(s) to which the statement of impact referred to.

The data set extracted data from 54 published papers, and contained 464 reports of impacts of warming on Mediterranean biota. Over half of the reports (276) referred to impacts following single warming events, such as heat waves, whereas the reports included 72 time series from which evidence of impacts of warming were derived. Where data were provided only in graphical form, the values were extracted from the figures using Graph Click $^{\mathrm{TM}}$ software.

The data on sea surface temperature provided by the studies reporting time series were introduced in the data set (SST). When these were not provided and in all the reports involving single events, SST was derived from satellite or modeled data. In particular, we computed the 99th percentile of the temperature observed for the year the reports referred to ( $\left.\mathrm{SST}_{\mathrm{p} 99}\right)$, which 
was expressed as an anomaly relative to the averaged august SST temperature computed for the period 1960-1985. The source of SST estimates was daily frequency SST estimates with a spatial resolution of $1 / 8^{\circ}(\sim 10 \mathrm{~km})$. For the period 1980-2011, we obtained SST data from satellite observations. In particular, we used the MyOcean reanalysis product which consists in a reprocessing of Pathfinder V5.2 (PFV52) AVHRR data (Casey et al., 2010) and provides daily gap-free maps (L4) of the foundation SST at the original PFV52 resolution at $1 / 24^{\circ}$ (Nardelli et al., 2013). In order to reduce observational noise, the resolution of the satellite data was degraded to $1 / 8^{\circ}$ through cell averaging. For the period 1960-1980, we obtained the SST data from outputs of an atmosphere-ocean regional climate model, the PROTHEUS system (Artale et al., 2010). The model is driven by ERA40 reanalysis fields at the lateral boundaries and provides daily means of SST for the period $1960-2000$ with a spatial resolution of $1 / 8^{\circ}$. The period $1980-$ 2000 has been used to calibrate the model outputs with satellite data in order to remove the model bias and to adjust the amplitude of the seasonal cycle. The calibrated model outputs for the period 1960-1980 were included in the database. In addition, the data set contains the annual maximum SST, the median August SST for the year(s) and location for each of the impact records, as well as the averaged august SST temperature computed for the period 1960-1985, which was used as a reference temperature to enable the calculation of anomalies.

To allow comparison among different estimates of the response of biological processes to warming we calculated, for each record the Activation Energy (E, in eV, Brown et al., 2004). For impacts derived from time series of changes in biological properties with temperature, the Activation Energy (E, in $\mathrm{eV}$ ) was derived as the slope of the Arrhenius equation,

$$
\ln (V)=C+\left[E *\left(\frac{1}{k T}\right)\right]
$$

where $V$ is the value of the biological parameter or rate process, $C$ is the intercept of the fitted regression equation, $k$ is the Boltzmann constant and $T$ is the temperature (in $K$ ). When $E$ was not provided, this was derived from linear regression analysis fitted using $\mathrm{JMP}^{\mathrm{TM}}$ software.

For records reporting impacts as properties observed during a thermal anomaly $\left(\mathrm{V}_{\mathrm{i}}\right)$ relative to a previous, reference, observation $\left(\mathrm{V}_{\mathrm{o}}\right)$ period, each characterized by SST $\mathrm{T}_{\mathrm{i}}$ and $\mathrm{T}_{\mathrm{o}}$ (in $\mathrm{K}$ ), respectively (where $\mathrm{T}_{\mathrm{o}}<\mathrm{T}_{\mathrm{i}}$ ), an effect size, equivalent to $\mathrm{E}$, was calculated, assuming the differences to conform to an

\section{REFERENCES}

Artale, V., Calmanti, S., Carillo, A., Dell'Aquila, A., Herrmann, M., Pisacane, G., et al. (2010). An atmosphere-ocean regional climate model for the Mediterranean area: assessment of a present climate
Arrhenius model, as:

$$
E=\frac{\ln \frac{V_{0}}{V_{i}}}{\frac{1}{k T_{i}}-\frac{1}{k T_{0}}}
$$

thereby allowing activation energies to be compared across properties and studies. Population dynamics reported as Mortality rates were recalculated to obtain survival rates to allow the calculations. When the trait decreased with temperature (e.g., net growth rates), the ratio was rearranged (i.e., $\ln \frac{V_{i}}{V_{0}}$ ) to provide all $\mathrm{E}$ estimates as positive values thereby facilitating comparison of effect size across biological traits.

The data set contains all of the metadata, biological response variables, activation energy calculations and reported and derived SST metrics, along with the reference of the papers the data are extracted from. The data set is downloaded as an Excel file $297 \mathrm{~Kb}$ in size with three different data sheets, (1) a sheet describing each of the columns in the data set, (2) the records reported as eventbased and time-series observations, and (3) reports on the years when communities or species presented abrupt shifts attributed to warming.

A full analysis and interpretation of the data re reported in Marbà et al. (2015a).

\section{AUTHOR CONTRIBUTIONS}

All authors designed the data set, compiled data and wrote the paper.

\section{FUNDING}

Spanish Ministry of Economy and Competitiveness (projects ESTRESX CTM2012-32603 and CLIMPACT CGL2014-54246C2-1-R). Ramón y Cajal contract (RYC-2013-14714) funded by the Spanish Ministry of Economy and Competitiveness and the Regional Government of the Balearic Islands.

\section{ACKNOWLEDGMENTS}

This research is a contribution to the ESTRESX (CTM201232603) and the CLIMPACT (CGL2014-54246-C2-1-R) projects funded by the Spanish Ministry of Economy and Competitiveness. We thank Coraline Girard and Xavier Carcelero for assistance during data compilation. GJ also acknowledges a Ramón y Cajal contract (RYC-201314714) funded by the Spanish Ministry of Economy and Competitiveness and the Regional Government of the Balearic Islands.

simulation. Clim. Dyn. 35, 721-740. doi: 10.1007/s00382-0090691-8.

Brown, J. H., Gillooly, J. F., Allen, A. P., Savage, V. M., and West, G. B. (2004). Toward a metabolic theory of ecology. Ecology 85, 1771-1789. doi: 10.1890/0 3-9000 
Casey, K. S., Brandon, T. B., Cornillon, P., and Evans, R. (2010). “The past, present and future of the AVHRR pathfinder SST program," in Oceanography from Space: Revisited, eds V. Barale, J. F. R. Gower, and L. Alberotanza (Dordrecht; Heidelberg; London; New York, NY: Springer), 273-287.

Marbà, N., Jordà, G., Agustí, S., Girard, C., and Duarte, C. M. (2015a). Footprints of climate change on Mediterranean Sea biota. Front. Mar. Sci. 2:00056. doi: 10.3389/fmars.2015.00056

Marbà, N., Jordà, G., Agustí, S., Girard, C., and Duarte, C. M. (2015b). Impacts of Climate Change on Organisms in the Mediterranean Sea [Dataset]. DIGITAL.CSIC. Available online at: http://hdl.handle.net/10261/116098

Nardelli, B. B., Tronconi, C., Pisano, A., and Santoleri, R. (2013). High and ultra-high resolution processing of satellite sea surface temperature data over Southern European Seas in the framework of
MyOcean project. Rem. Sens. Env. 129, 1-16. doi: 10.1016/j.rse.2012. 10.012

Conflict of Interest Statement: The authors declare that the research was conducted in the absence of any commercial or financial relationships that could be construed as a potential conflict of interest.

Copyright (c) 2016 Marbà, Jordà, Agustí and Duarte. This is an open-access article distributed under the terms of the Creative Commons Attribution License (CC BY).

The use, distribution or reproduction in other forums is permitted, provided the original author(s) or licensor are credited and that the original publication in this journal is cited, in accordance with accepted academic practice. No use, distribution or reproduction is permitted which does not comply with these terms. 